\title{
PENERAPAN DATA MINING MENGGUNAKAN ALGORITMA C4.5 TEHADAP PENGARUH PENJUALAN KOPI PADA PT. JPW INDONESIA
}

\author{
Ikong Ifongki \\ Sistem Informasi: STMIK Nusa Mandiri Jakarta; \\ Jl. Damai No 8 Warung Jati Barat (Margasatwa), Pasar Minggu, Jakarta Selatan \\ 12540, 0217883 9513; \\ e-mail: ikongifongki@gmail.com
}

\begin{abstract}
Data mining is a series of processes to explore the added value of a data set in the form of knowledge that has not been known manually. The use of data mining techniques is expected to provide knowledge - knowledge that was previously hidden in the data warehouse, so that it becomes valuable information. C4.5 algorithm is a decision tree classification algorithm that is widely used because it has the main advantages of other algorithms. The advantages of the C4.5 algorithm can produce decision trees that are easily interpreted, have an acceptable level of accuracy, are efficient in handling discrete type attributes and can handle discrete and numeric type attributes. The output of the C4.5 algorithm is a decision tree like other classification techniques, a decision tree is a structure that can be used to divide a large data set into smaller sets of records by applying a series of decision rules, with each series of division members of the resulting set become similar to each other. In this case study what is discussed is the effect of coffee sales by processing 106 data from 1087 coffee sales data at PT. JPW Indonesia. Data samples taken will be calculated manually using Microsoft Excel and Rapidminer software. The results of the calculation of the C4.5 algorithm method show that the Quantity and Price attributes greatly affect coffee sales so that sales at PT. JPW Indonesia is still often unstable.
\end{abstract}

Keywords: Data Mining, C4.5 Algorithm, Coffee Sales

\section{PENDAHULUAN}

Semakin banyaknya persaingan dalam dunia bisnis khususnya dalam industri penjualan menuntut pihak manajemen untuk putar otak mencari peluang untuk tetap berkecimpung dalam bisnisnya. Untuk menyiasati hal tersebut, tentunya pihak manajemen harus mampu menganalisa suatu data yang ada untuk di jadikan bahan acuan untuk menganalisa data tersebut (Badrul, 2016).

Kopi merupakan salah satu komoditi yang banyak dibudidayakan oleh system yang berada di kawasan system Benua Afrika, Amerika Tengah dan Selatan serta di Asia Pasifik. Keberadaan komditas kopi ini banyak diusahakan oleh banyak pihak sesuai dengan tingkat kebutuhan baik dari sisi jumlah maupun jenisnya, 
sehingga terdapat dua jenis kopi yang banyak dikenal yaitu kopi arabika dan kopi robusta. Kopi arabika, sebagian besar bearasal dari Colombia, system- system Amerika tengah dan Brazil. Sedangkan kopi robusta berasal dari Afrika dan Asia Pasifik. Terdapat berbagai jenis kopi dari Indonesia yang sangat terkenal di dunia dan menjadi sumber kebanggaan di Nusantara seperti kopi luwak, kopi Java, kopi Toraja, kopi Sumatera, kopi Kintamani, kopi Lanang, kopi Wamena, kopi Gayo, kopi Jember dan lain-lain. Jenis-jenis kopi ini memiliki pilihan rasa yang mampu bersaing di pasaran serta pengolahan yang unik seperti kopi gayo asal Aceh, kopi jenis ini dipandang sebagai kopi kelas premium dengan tempat penaman di dataran tinggi yang memberi manfaat tersendiri terhadap kualitas kopi yang dimilikinya. Hal tersebut mengingat kopi terbaik dipengaruhi oleh tempat penanaman yang ditandai dengan semakin tinggi dataran tempat menanam maka semakin baik pula kualitas biji kopi yang didapat (Fauziah et al., 2014).

PT. JPW Indonesia merupakan perusahaan kopi Indonesia yang focus menjual Specialty Coffee Indonesia. PT. JPW Indonesia menjual berbagai jenis macam kopi, dari pulau sumatera sampai pulau papua. PT. JPW Indonesia memiliki kualitas kopi yang stabil dan juga telah memilih supplier - supplier terpercaya untuk bekerjasama. Semua sumber telah di seleksi secara ketat baik secara kualitas, professional, dan kestabilan suplai tanpa perlu mengkhawatirkan terhadap kualitas kopi yang menurun. Penjualan kopi di PT. JPW Indonesia masih naik turun atau tidak konsisten setiap bulannya dan masih mengalami kesulitan dalam memprediksi penjualan kopi setiap bulannya, penjualan yang tidak stabil bisa disebabkan baik itu dari pembeli, jenis kopi, quantity, harga dll. Sehingga modal atau cost tidak sesuai dengan keuntungan.

Pemanfaatan data yang ada di dalam system informasi untuk menunjang kegiatan pengambilan keputusan, tidak cukup hanya mengandalkan data operasional saja, diperlukan suatu analisis data untuk menggali potensi - potensi informasi yang ada. Para pengambil keputusan berusaha untuk memanfaatkan gudang data yang sudah dimiliki untuk menggali informasi yang berguna membantu mengambil keputusan, hal ini mendorong munculnya cabang ilmu baru untuk mengatasi masalah penggalian informasi atau pola yang penting atau menarik dari data dalam jumlah besar, yang disebut dengan data mining. Penggunaan teknik data mining diharapkan dapat memberikan pengetahuan - pengetahuan yang sebelumnya tersembunyi 
didalam gudang data sehingga menjadi informasi yang berharga. Algoritma C4.5 merupakan algoritma klasifikasi pohon keputusan yang banyak digunakan karena memiliki kelebihan utama dari algoritma yang lainnya. Kelebihan algoritma C4.5 dapat menghasilkan pohon keputusan yang mudah diinterprestasikan, memiliki tingkat akurasi yang dapat diterima, efisien dalam menangani atribut bertipe diskret dan dapat menangani atribut bertipe diskret dan numeric (Zahedi, Nahid-Mobarakeh, Pierfederici, \& Norum, 2016)

\section{METODE PENELITIAN}

Teknik pengumpulan data yang digunakan dalam penelitian adalah Observasi merupakan metode yang dilakukan penulis dengan cara mengumpulkan data dan informasi yang dibutuhkan langsung di PT. JPW Indonesia, dengan acuan menganalisa semua proses kegiatan transaksi penjualan. Wawancara untuk mendapatkan data - data yang benar dan akurat, maka penulis melakukuan sesi tanya jawab secara langsung terhadap manager di PT. JPW Indonesia, yang berkaitan dengan semua proses penjualan baik secara online maupun offline, sampai proses laporan harian. Studi Pustaka digunakan untuk mengumpulkan data - data dari penelitian terdahulu, pembelajaran dari berbagai dokumen seperti buku - buku, jurnal, teori - toeri yang mendukung penelitian ini. Guna untuk membantu peneliti dalam menentukan landasan berpikir dan sebagai pijakan yang kuat dalam membangun kerangka berpikir.

Langkah - Langkah Penelitian, supaya penelitian ini dapat dilakukan secara terstruktur maka dibuat langkah - langkah penelitian yang terdiri dari: 1) Pengumpulan Data, pengumpulan data dilakukan dengan cara mengumpulkan datadata yang dibutuhkan dan akan digunakan untuk proses algoritma C4.5. 2) Seleksi Data, seleksi data yang dilakukan dengan cara memilih data yang sudah dikumpulkan pada langkah sebelumnya, tujuan dari seleksi data adalah untuk menghasilkan himpunan data target, menghasilkan pemilihian himpunan data, atau memfokuskan pada sampel data yang akan digunakan untuk proses seleksi. 3) Transformasi Data, transformasi data dilakukan dengan cara melakukan proses mentransformasi atau mengubah data ke dalam bentuk yang sesuai, supaya data tersebut dapat diproses dengan perhitungan algoritma C4.5. 4) Perhitungan Entropy dan Gain, setelah melakukan transformasi data kemudai adilakukan 
perhitungan dari semua atribut, dari hasil perhitungan gain, nilai tertinggi dari hasil perhitungan akan di jadikan root/akar pada pembuatan pohon keputusan. 5) Pohon Keputusan (decision tree), hasil dari perhitungan entropy dan gain akan menghasilkan pohon keputusan. Perhitungan dilakuka berulang-ulang sampai semua atribut tidak memiliki kelas dan tidak bisa di lakukan perhitungan lagi. 6) Aturanaturan atau Rule Model, setelah menghasilkan pohon keputusan kemudian terbentuklah aturan-aturan rule model yang berupa uraian dan penjelasan yang mempresentasikan sebuah pohon keputusan yang diteliti 7) Validasi dan Pengujian, langkah selanjutnya melakukan pengujian, hal ini dilakukan untuk mengetahui semua fungsi bekerja dengna baik atau tidak.

\section{Menentukan Kerangka Berpikir}

Kerangka pemikiran adalah gambaran penelitian yang dilakukan dan sebagai acuan peneliti dalam melakukan penelitian terhadap pengaruh penjualan di PT. JPW Indonesia. Kerangka pemikiran ini dilakukan dari beberapa tahap. Tahapan pertama adalah mulai, tahapan kedua yaitu istrumen penelitian, tahapan ketiga pengumpulan data, tahapan keempata data primer dan data sekunder, tahapan kelima pengolahan data dengan algoritma $\mathrm{C} 4.5$, tahapan keenam kesimpulan dan saran, dan tahapan terkahir yaitu selesai.

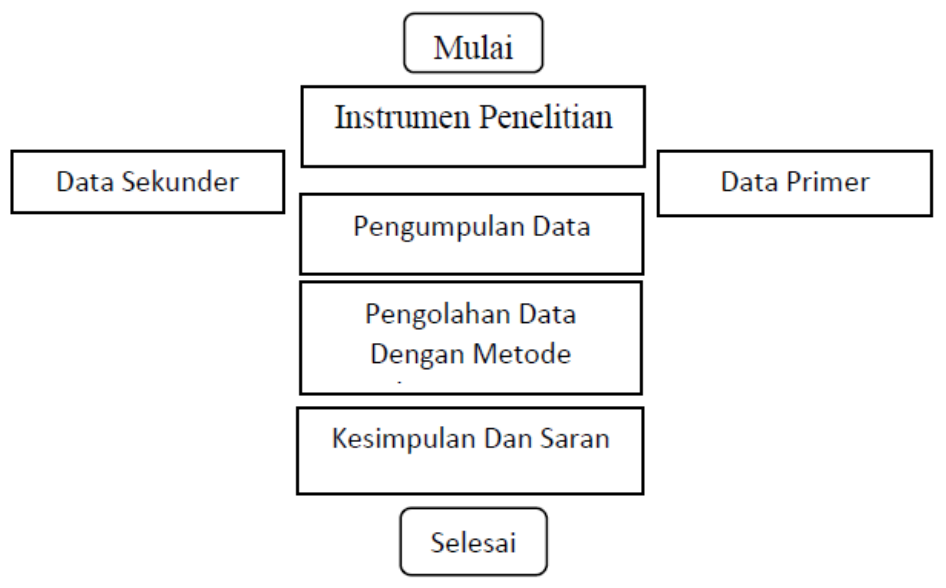

\section{Pengumpulan Data}

Pada pengumpulan data dijelaskan tentang bagaimana dan dari mana data dalam penelitian ini didapatkan, ada dua tipe dalam pengumpulan data, yaitu, pengumpulan data primer dan pengumpulan data sekunder. Data primer merupakan sumber data penelitian yang diperoleh secara langsung dari sumber asli (tidak 
melalui media perantara), berupa opini objek (orang) secara individual atau kelompok, hasil observasi terhadap suatu benda (fisik), kejadian atau kegiatan, dan hasil pengujian. Dalam pengumpulan data primer dalam penelitian ini menggunakan observasi, wawancara, dan studi pustaka. Data sekunder adalah sumber data penelitian yang diperoleh peneliti secara tidak langsung melalui media perantara (diperoleh dan dicatat oleh pihak lain). Data-data sekunder dalam penelitian ini merupakan data-data yang diperoleh dari hasil penelusuran basis data dari PT. JPW Indonesia yang bersangkutan, tulisan-tulisan internet, ataupun data lain yang relevan. Pengumpulan data sekunder dalam penelitian ini adalah teknik dokumentasi, riset kepustakaan, dan penelitian lapangan (Prof. Dr. Sugiyono, 2017).

\section{Populasi Penelitian}

Populasi adalah wilayah generalisasi yang terjadi atas: proyek/subyek yang mempunyai kualitas dan karakteristik tertentu yang ditetapkan oleh peneliti untuk dipelajari dan kemudian ditarik kesimpulannya. Jadi populasi bukan hanya orang, tetapi juga obyek/subyek yang dipelajari, tetapi meliputi seluruh karakteristik/sifat yang dimiliki oleh subyek atau obyek tersebut (Prof. Dr. Sugiyono, 2017b). Populasi yang digunakan dalam penelitian ini adalah jumlah keseluruhan data penjualan kopi pada PT. JPW Indonesia dari awal Janurai 2019 - akhir Februari 2019.

\section{Sampel Penelitian}

Data sampel diambil dari data penjualan kopi di PT. JPW Indonesia, data penjualan kopi dari periode awal Janurai 2019 - akhir Februari 2019. Dari 1087 data dan hanya 106 data yang akan digunakan peneliti untuk dijadikan sampel. 
HASIL DAN PEMBAHASAN

Tabel 1. Data Penjualan Kopi PT. JPW Indonesia

\begin{tabular}{|c|c|c|c|c|c|c|}
\hline No & Tanggal & Pembeli & Jenis Kopi & Quantity & Harga & Keterangan \\
\hline 1 & 02/01/2019 & Reseller & Arabica & $250 \mathrm{gr}$ & 71,500 & Offline \\
\hline 2 & $02 / 01 / 2019$ & Individu & Robusta & $500 \mathrm{gr}$ & 77,000 & Offline \\
\hline 3 & 02/01/2019 & Individu & Blend & $1000 \mathrm{gr}$ & 181,500 & Offline \\
\hline 4 & 02/01/2019 & Reseller & Blend & $250 \mathrm{gr}$ & 49,500 & Online \\
\hline 5 & $02 / 01 / 2019$ & Reseller & Arabica & $250 \mathrm{gr}$ & 71,500 & Online \\
\hline 6 & $02 / 01 / 2019$ & Reseller & Arabica & $250 \mathrm{gr}$ & 71,500 & Online \\
\hline 7 & $02 / 01 / 2019$ & Individu & Robusta & $250 \mathrm{gr}$ & 38,500 & Online \\
\hline 8 & $02 / 01 / 2019$ & Individu & Robusta & $500 \mathrm{gr}$ & 77,000 & Online \\
\hline 9 & $02 / 01 / 2019$ & Individu & Arabica & $500 \mathrm{gr}$ & 143,000 & Online \\
\hline 10 & $02 / 01 / 2019$ & Individu & Arabica & $250 \mathrm{gr}$ & 71,500 & Offline \\
\hline 11 & $02 / 01 / 2019$ & Reseller & Blend & $1000 \mathrm{gr}$ & 181,500 & Offline \\
\hline 12 & $02 / 01 / 2019$ & Reseller & Robusta & $1000 \mathrm{gr}$ & 143,000 & Offline \\
\hline 13 & 02/01/2019 & Reseller & Robusta & $1000 \mathrm{gr}$ & 143,000 & Offline \\
\hline 14 & 02/01/2019 & Reseller & Robusta & $1000 \mathrm{gr}$ & 143,000 & Offline \\
\hline 15 & 02/01/2019 & Reseller & Robusta & $1000 \mathrm{gr}$ & 143,000 & Offline \\
\hline 16 & $02 / 01 / 2019$ & Reseller & Robusta & $1000 \mathrm{gr}$ & 143,000 & Offline \\
\hline 17 & $02 / 01 / 2019$ & Reseller & Robusta & $1000 \mathrm{gr}$ & 143,000 & Offline \\
\hline 18 & $02 / 01 / 2019$ & Reseller & Robusta & $1000 \mathrm{gr}$ & 143,000 & Offline \\
\hline 19 & $02 / 01 / 2019$ & Individu & Robusta & $250 \mathrm{gr}$ & 38,500 & Offline \\
\hline 20 & 02/01/2019 & Individu & Robusta & $250 \mathrm{gr}$ & 38,500 & Offline \\
\hline 21 & $02 / 01 / 2019$ & Individu & Arabica & $250 \mathrm{gr}$ & 71,500 & Online \\
\hline 22 & $02 / 01 / 2019$ & Reseller & Arabica & $1000 \mathrm{gr}$ & 257,400 & Offline \\
\hline 23 & $02 / 01 / 2019$ & Reseller & Blend & $1000 \mathrm{gr}$ & 181,500 & Offline \\
\hline 24 & 03/01/2019 & Reseller & Blend & $1000 \mathrm{gr}$ & 181,500 & Offline \\
\hline 25 & 03/01/2019 & Reseller & Arabica & $1000 \mathrm{gr}$ & 257,400 & Offline \\
\hline 26 & $03 / 01 / 2019$ & Reseller & Robusta & $1000 \mathrm{gr}$ & 143,000 & Online \\
\hline 27 & $03 / 01 / 2019$ & Reseller & Blend & $1000 \mathrm{gr}$ & 181,500 & Offline \\
\hline 28 & 03/01/2019 & Reseller & Blend & $1000 \mathrm{gr}$ & 181,500 & Offline \\
\hline 29 & $03 / 01 / 2019$ & Reseller & Blend & $1000 \mathrm{gr}$ & 181,500 & Offline \\
\hline 30 & 03/01/2019 & Reseller & Blend & $1000 \mathrm{gr}$ & 181,500 & Offline \\
\hline
\end{tabular}




\begin{tabular}{|c|c|c|c|c|c|c|}
\hline 31 & $03 / 01 / 2019$ & Reseller & Blend & $1000 \mathrm{gr}$ & 181,500 & Offline \\
\hline 32 & 03/01/2019 & Reseller & Blend & $1000 \mathrm{gr}$ & 181,500 & Offline \\
\hline 33 & 03/01/2019 & Reseller & Blend & $1000 \mathrm{gr}$ & 181,500 & Offline \\
\hline 34 & 03/01/2019 & Reseller & Blend & $1000 \mathrm{gr}$ & 181,500 & Online \\
\hline 35 & 03/01/2019 & Reseller & Blend & $1000 \mathrm{gr}$ & 181,500 & Online \\
\hline 36 & $03 / 01 / 2019$ & Individu & Blend & $250 \mathrm{gr}$ & 49,500 & Online \\
\hline 37 & 03/01/2019 & Individu & Blend & $250 \mathrm{gr}$ & 49,500 & Online \\
\hline 38 & 03/01/2019 & Reseller & Robusta & $1000 \mathrm{gr}$ & 143,000 & Online \\
\hline 39 & 03/01/2019 & Reseller & Robusta & $250 \mathrm{gr}$ & 38,500 & Online \\
\hline 40 & 03/01/2019 & Individu & Arabica & $250 \mathrm{gr}$ & 71,500 & Online \\
\hline 41 & $03 / 01 / 2019$ & Individu & Arabica & $250 \mathrm{gr}$ & 71,500 & Online \\
\hline 42 & 03/01/2019 & Reseller & Arabica & $250 \mathrm{gr}$ & 71,500 & Online \\
\hline 43 & 03/01/2019 & Reseller & Arabica & $250 \mathrm{gr}$ & 71,500 & Online \\
\hline 44 & 03/01/2019 & Individu & Arabica & $250 \mathrm{gr}$ & 71,500 & Online \\
\hline 45 & 03/01/2019 & Individu & Arabica & $250 \mathrm{gr}$ & 71,500 & Online \\
\hline 46 & 03/01/2019 & Individu & Arabica & $250 \mathrm{gr}$ & 71,500 & Online \\
\hline 47 & 03/01/2019 & Individu & Arabica & $250 \mathrm{gr}$ & 71,500 & Online \\
\hline 48 & 03/01/2019 & Individu & Arabica & $250 \mathrm{gr}$ & 71,500 & Online \\
\hline 49 & $04 / 01 / 2019$ & Reseller & Arabica & $1000 \mathrm{gr}$ & 257,400 & Online \\
\hline 50 & $04 / 01 / 2019$ & Reseller & Blend & $1000 \mathrm{gr}$ & 181,500 & Online \\
\hline 51 & $04 / 01 / 2019$ & Reseller & Robusta & $1000 \mathrm{gr}$ & 143,000 & Online \\
\hline 52 & $04 / 01 / 2019$ & Reseller & Robusta & $1000 \mathrm{gr}$ & 143,000 & Offline \\
\hline 53 & $04 / 01 / 2019$ & Reseller & Blend & $1000 \mathrm{gr}$ & 181,500 & Offline \\
\hline 54 & $04 / 01 / 2019$ & Reseller & Blend & $1000 \mathrm{gr}$ & 181,500 & Offline \\
\hline 55 & $04 / 01 / 2019$ & Reseller & Blend & $1000 \mathrm{gr}$ & 181,500 & Offline \\
\hline 56 & 04/01/2019 & Reseller & Arabica & $1000 \mathrm{gr}$ & 257,400 & Offline \\
\hline 57 & $04 / 01 / 2019$ & Reseller & Arabica & $1000 \mathrm{gr}$ & 257,400 & Offline \\
\hline 58 & $04 / 01 / 2019$ & Reseller & Arabica & $1000 \mathrm{gr}$ & 257,400 & Offline \\
\hline 59 & $04 / 01 / 2019$ & Reseller & Arabica & $1000 \mathrm{gr}$ & 257,400 & Offline \\
\hline 60 & $04 / 01 / 2019$ & Reseller & Blend & $1000 \mathrm{gr}$ & 181,500 & Offline \\
\hline 61 & $04 / 01 / 2019$ & Reseller & Blend & $1000 \mathrm{gr}$ & 181,500 & Offline \\
\hline 62 & $04 / 01 / 2019$ & Reseller & Blend & $1000 \mathrm{gr}$ & 181,500 & Offline \\
\hline 63 & $04 / 01 / 2019$ & Reseller & Robusta & $1000 \mathrm{gr}$ & 143,000 & Offline \\
\hline 64 & 04/01/2019 & Reseller & Robusta & $1000 \mathrm{gr}$ & 143,000 & Offline \\
\hline
\end{tabular}




\begin{tabular}{|c|c|c|c|c|c|c|}
\hline 65 & $04 / 01 / 2019$ & Reseller & Arabica & $1000 \mathrm{gr}$ & 257,400 & Offline \\
\hline 66 & $04 / 01 / 2019$ & Reseller & Blend & $1000 \mathrm{gr}$ & 181,500 & Offline \\
\hline 67 & 04/01/2019 & Individu & Blend & $250 \mathrm{gr}$ & 49,500 & Online \\
\hline 68 & $04 / 01 / 2019$ & Individu & Blend & $250 \mathrm{gr}$ & 49,500 & Online \\
\hline 69 & 04/01/2019 & Individu & Blend & $250 \mathrm{gr}$ & 49,500 & Online \\
\hline 70 & 04/01/2019 & Individu & Blend & $250 \mathrm{gr}$ & 49,500 & Online \\
\hline 71 & $04 / 01 / 2019$ & Individu & Arabica & $250 \mathrm{gr}$ & 71,500 & Online \\
\hline 72 & $05 / 01 / 2019$ & Individu & Arabica & $250 \mathrm{gr}$ & 71,500 & Online \\
\hline 73 & $05 / 01 / 2019$ & Individu & Arabica & $250 \mathrm{gr}$ & 71,500 & Online \\
\hline 74 & $05 / 01 / 2019$ & Individu & Arabica & $250 \mathrm{gr}$ & 71,500 & Online \\
\hline 75 & 05/01/2019 & Individu & Arabica & $250 \mathrm{gr}$ & 71,500 & Online \\
\hline 76 & $05 / 01 / 2019$ & Individu & Arabica & $250 \mathrm{gr}$ & 71,500 & Online \\
\hline 77 & $05 / 01 / 2019$ & Reseller & Arabica & $1000 \mathrm{gr}$ & 257,400 & Online \\
\hline 78 & $05 / 01 / 2019$ & Reseller & Arabica & $1000 \mathrm{gr}$ & 257,400 & Online \\
\hline 79 & 05/01/2019 & Reseller & Arabica & $1000 \mathrm{gr}$ & 257,400 & Offline \\
\hline 80 & $05 / 01 / 2019$ & Reseller & Arabica & $1000 \mathrm{gr}$ & 257,400 & Offline \\
\hline 81 & 05/01/2019 & Reseller & Arabica & $1000 \mathrm{gr}$ & 257,400 & Offline \\
\hline 82 & $05 / 01 / 2019$ & Reseller & Arabica & $1000 \mathrm{gr}$ & 257,400 & Offline \\
\hline 83 & 05/01/2019 & Reseller & Arabica & $1000 \mathrm{gr}$ & 257,400 & Offline \\
\hline 84 & $05 / 01 / 2019$ & Reseller & Arabica & $1000 \mathrm{gr}$ & 257,400 & Offline \\
\hline 85 & $05 / 01 / 2019$ & Reseller & Blend & $1000 \mathrm{gr}$ & 181,500 & Offline \\
\hline 86 & $05 / 01 / 2019$ & Reseller & Arabica & $1000 \mathrm{gr}$ & 257,400 & Offline \\
\hline 87 & $05 / 01 / 2019$ & Reseller & Arabica & $1000 \mathrm{gr}$ & 257,400 & Offline \\
\hline 88 & $05 / 01 / 2019$ & Reseller & Arabica & $1000 \mathrm{gr}$ & 257,400 & Offline \\
\hline 89 & $07 / 01 / 2019$ & Reseller & Arabica & $1000 \mathrm{gr}$ & 257,400 & Offline \\
\hline 90 & 07/01/2019 & Reseller & Arabica & $1000 \mathrm{gr}$ & 257,400 & Offline \\
\hline 91 & 07/01/2019 & Reseller & Arabica & $1000 \mathrm{gr}$ & 257,400 & Offline \\
\hline 92 & 07/01/2019 & Reseller & Arabica & $1000 \mathrm{gr}$ & 257,400 & Offline \\
\hline 93 & 07/01/2019 & Reseller & Arabica & $1000 \mathrm{gr}$ & 257,400 & Offline \\
\hline 94 & $07 / 01 / 2019$ & Reseller & Arabica & $1000 \mathrm{gr}$ & 257,400 & Offline \\
\hline 95 & 07/01/2019 & Individu & Arabica & $250 \mathrm{gr}$ & 71,500 & Offline \\
\hline 96 & $07 / 01 / 2019$ & Individu & Blend & $250 \mathrm{gr}$ & 49,500 & Offline \\
\hline 97 & $07 / 01 / 2019$ & Individu & Blend & $250 \mathrm{gr}$ & 49,500 & Online \\
\hline 98 & $07 / 01 / 2019$ & Individu & Blend & $250 \mathrm{gr}$ & 49,500 & Online \\
\hline
\end{tabular}




\begin{tabular}{|c|c|c|c|c|c|l|}
\hline 99 & $07 / 01 / 2019$ & Individu & Blend & $500 \mathrm{gr}$ & 99,000 & Offline \\
\hline 100 & $07 / 01 / 2019$ & Individu & Blend & $500 \mathrm{gr}$ & 99,000 & Offline \\
\hline 101 & $07 / 01 / 2019$ & Individu & Blend & $500 \mathrm{gr}$ & 99,000 & Offline \\
\hline 102 & $07 / 01 / 2019$ & Individu & Blend & $250 \mathrm{gr}$ & 49,500 & Online \\
\hline 103 & $07 / 01 / 2019$ & Individu & Blend & $250 \mathrm{gr}$ & 49,500 & Offline \\
\hline 104 & $07 / 01 / 2019$ & Individu & Blend & $250 \mathrm{gr}$ & 49,500 & Offline \\
\hline 105 & $07 / 01 / 2019$ & Reseller & Robusta & $1000 \mathrm{gr}$ & 143,000 & Offline \\
\hline 106 & $07 / 01 / 2019$ & Reseller & Robusta & $1000 \mathrm{gr}$ & 143,000 & Online \\
\hline
\end{tabular}

Sumber: PT. JPW Indonesia

\section{Perhitungan Algoritma C4.5 dengan Microsoft Excel}

\begin{tabular}{|c|c|c|c|c|c|c|}
\hline$\Delta$ & A & B & C & $\mathrm{D}$ & E & $\mathrm{F}$ \\
\hline 1 & \multicolumn{6}{|c|}{ Node 1} \\
\hline 2 & jumlah kasus (S) & 106 & & & & \\
\hline 3 & jumlah kasus - Online (s1) & 42 & & & & \\
\hline 4 & jumlah kasus - Offline (s2) & 64 & & & & \\
\hline \multicolumn{7}{|l|}{5} \\
\hline \multicolumn{7}{|l|}{6} \\
\hline 7 & \multicolumn{2}{|l|}{ Online } & & & \multicolumn{2}{|c|}{ Offline } \\
\hline 8 & $\mathrm{~s} 1 / \mathrm{s}$ & 0.396226415 & & & $\mathrm{~s} 2 / \mathrm{s}$ & 0.603773585 \\
\hline 9 & $\log \mathrm{s} 1 / \mathrm{s}$ & -1.335603032 & & & $\log \mathrm{s} 2 / \mathrm{s}$ & -0.727920455 \\
\hline 10 & Rumus Entropy & 0.529201201 & & & Rumus Entrpoy & 0.439499142 \\
\hline \multicolumn{7}{|l|}{11} \\
\hline \multicolumn{7}{|l|}{12} \\
\hline 13 & Entropy Total & 0.968700344 & & & & \\
\hline
\end{tabular}

Perhitungan Entropy dan Gain node 1

Gambar 1. entropy total node 1

Entropi $(S)=\sum_{j=1}^{k}-p_{j} \log _{2} p_{j}$

Jumlah kasus $=\mathrm{S}$

Jumlah kasus - online $=$ s1 Jumlah kasus - offline $=\mathrm{s} 2$

Online $: \mathrm{s} 1 / \mathrm{S}=\mathrm{B} 3 / \mathrm{B} 2=0,396226415$

$\log s 1 / \mathrm{S}=\log (\mathrm{B} 8,2)=-1,335603032$

Rumus Entropy $=(-\mathrm{B} 8) * \mathrm{~B} 9=0,529201201$

Offline $: \mathrm{s} 2 / \mathrm{S}=\mathrm{B} 4 / \mathrm{B} 2=0,603773585$

$\log s 1 / S=\log (F 8,2)=-0,727920455$

Rumus Entropy $=(-\mathrm{F} 8) * \mathrm{~F} 9=0,439499142$

Entropy Total $=\mathrm{B} 10+\mathrm{F} 10=\mathbf{0 , 9 6 8 7 0 0 3 4 4}$ 


\begin{tabular}{c|l|r|r|r|r|}
\multicolumn{2}{|c|}{ A } & \multicolumn{2}{c|}{ B } & \multicolumn{1}{c|}{ C } & \multicolumn{1}{c|}{ E } \\
\hline 1 & Entropy Total & 0.968700344 & & & \\
\hline 2 & & & & & \\
\hline 3 & Entropy Atribut Reseller & 68 & 106 & 0.787126586 & 0.504949131 \\
\hline 4 & Entropy Atribut Individu & 40 & 106 & 0.905334183 & 0.341635541 \\
\hline 5 & & & & & \\
\hline 6 & & & & & 0.846584672 \\
\hline 7 & & & & & \\
\hline 8 & Grand Total Entropy Atribut & 108 & & & 0.968700344 \\
\hline 9 & & & & & $\mathbf{0 . 1 2 2 1 1 5 6 7 2}$ \\
\hline 10 & Nilai Gain S & -107.0312997 & & & \\
\hline & & & & & \\
\hline
\end{tabular}

\section{Perhitungan Gain node 1}

Gambar 2. gain pembeli node 1

Gain $(\mathrm{S}, \mathrm{A})=$ Entrophy $(\mathrm{s})-\sum_{\mathrm{i}=1}^{\mathrm{n}}-\frac{\mid \mathrm{si}}{|\mathrm{S}|} *$ Entrophy $(\mathrm{si})$

Entropy Total $==+$ sheet $2 ! E 3=0,968700344$

Jumlah kasus keseluruhan $=106$

Jumlah kasus reseller $=68$

Jumlah kasus individu $=40$

Entropy reseller $==+$ sheet 2 !E $5=0,787126586$

Maka $=(\mathrm{B} 3 / \mathrm{C} 3) * \mathrm{D} 3=\mathbf{0 , 5 0 4 9 4 9 1 3 1}$

Entropy individu $==+$ sheet 2 !E $6=0,905334183$

Maka $=(\mathrm{B} 4 / \mathrm{C} 4) * \mathrm{D} 4=\mathbf{0 , 3 4 1 6 3 5 5 4 1}$

$=\mathrm{SUM}(\mathrm{E} 3: \mathrm{E} 4)=\mathbf{0 , 8 4 6 5 8 4 6 7 2}$

Jadi Gain pembeli node $1=0,95479307-0,857427642=\mathbf{0 , 1 2 2 1 1 1 5 6 7 2}$ 


\section{Hasil perhitungan entropy dan gain node 1}

\begin{tabular}{|c|c|c|c|c|c|c|}
\hline 3 & Total & $\mathbf{1 0 6}$ & $\mathbf{4 2}$ & $\mathbf{6 4}$ & $\mathbf{0 . 9 6 8 7 0}$ & \\
\hline 4 & Nilai & Jum lah Kasus & Online & Offline & Entropy & Gain \\
\hline 5 & Reseller & 68 & 16 & 52 & 0.787126586 & \\
\hline 6 & Individu & 38 & 26 & 14 & 0.905334183 & 0.12212 \\
\hline 7 & & & & & \\
\hline 8 & Arabica & 47 & 22 & 26 & 0.985134821 & \\
\hline 9 & Robusta & 20 & 7 & 14 & 0.890301831 & \\
\hline 10 & Blend & 38 & 14 & 25 & 0.928152615 & 0.00473 \\
\hline 11 & & & & & & \\
\hline 12 & $250 g r$ & 38 & 30 & 8 & 0.74248757 & \\
\hline 13 & $500 g r$ & 6 & 3 & 4 & 0.889975 & \\
\hline 14 & $1000 g r$ & 62 & 11 & 52 & 0.655447652 & 0.64375 \\
\hline 15 & & & & & & \\
\hline 16 & $>100 \mathrm{rb}$ & 63 & 12 & 51 & 0.702466551 & \\
\hline 17 & $<=100 \mathrm{rb}$ & 45 & 31 & 14 & 0.894451885 & 0.17148 \\
\hline 18 & & & & & & \\
\hline
\end{tabular}

Gambar 3. Tabel hasil perhitungan entropy dan gain node 1

Dari hasil perhitungan diatas maka Gain node 1 tertinggi adalah Quantity dengan nilai 0,64375 .

\section{Perhitungan Entropy dan gain node 1.1}

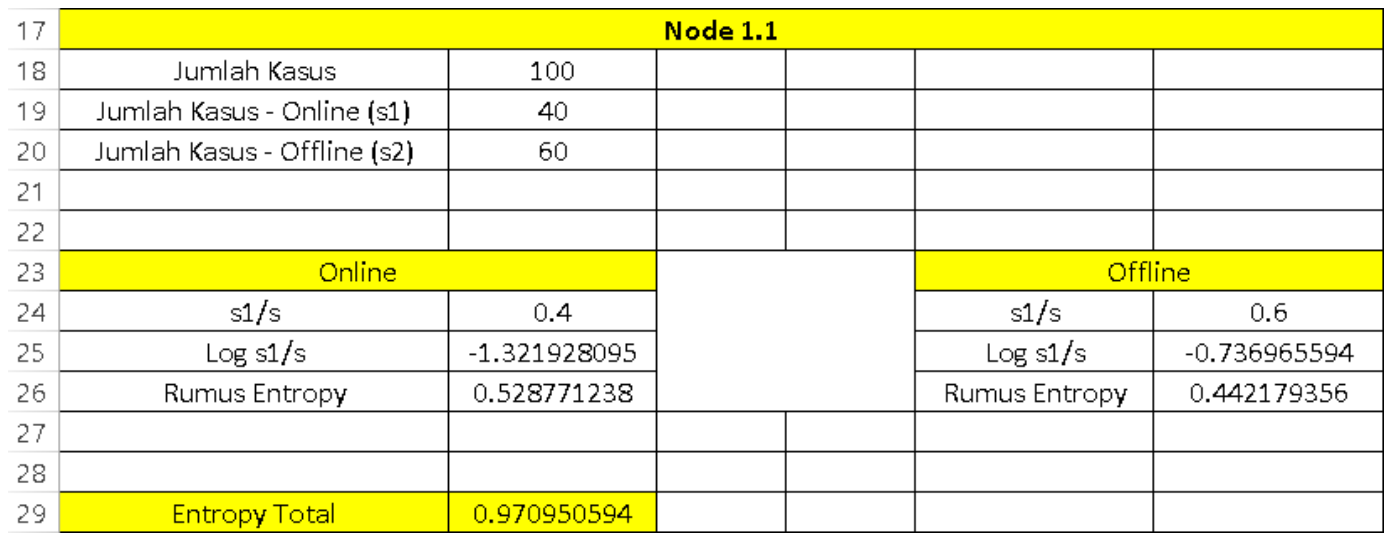

Gambar 4. entropy total node 1.1

Jumlah kasus $=\mathrm{S}$

Jumlah kasus - online $=\mathrm{s} 1$

Jumlah kasus - offline $=\mathrm{s} 2$

Online $: \mathrm{s} 1 / \mathrm{S}=\mathrm{B} 19 / \mathrm{B} 18=0,4$

$\log \mathrm{s} 1 / \mathrm{S}=\log (\mathrm{B} 24,2)=-1,321928095$

Rumus Entropy $=(-\mathrm{B} 24) * \mathrm{~B} 25=0,528771238$ 
Offline : $\mathrm{s} 2 / \mathrm{S}=\mathrm{B} 20 / \mathrm{B} 18=0,6$

$\log \mathrm{s} 1 / \mathrm{S}=\log (\mathrm{B} 24,2)=-0,736965594$

Rumus Entropy $=(-\mathrm{F} 24) * \mathrm{~F} 25=0,442179356$

Entropy Total $=\mathrm{B} 26+\mathrm{F} 26=\mathbf{0 , 9 7 0 9 5 0 5 9 4}$

\section{Perhitungan gain node 1.1}

\begin{tabular}{|c|c|c|c|c|c|}
\hline 14 & \multicolumn{5}{|c|}{ Node 1.1} \\
\hline 15 & Entropy Atribut Reseller & 68 & 100 & 0.787126586 & 0.535246079 \\
\hline 16 & Entropy Atribut Individu & 32 & 100 & 0.857148437 & 0.2742875 \\
\hline 17 & & & & & \\
\hline 18 & & & & & 0.809533579 \\
\hline 19 & & & & & \\
\hline 20 & Grand Total Atribut Entropy & 100 & & & 0.970950594 \\
\hline 21 & & & & & 0.161417016 \\
\hline 22 & Nilai Gain S & 99.02904941 & & & \\
\hline
\end{tabular}

Gambar 5. gain pembeli node 1.1

Entropy Total $==+$ sheet 2 !N3 $=0,970950594$

Jumlah kasus keseluruhan $=100$

Jumlah kasus reseller $=68$

Jumlah kasus individu $=32$

Entropy reseller $==+$ sheet $2 ! \mathrm{N} 5=0,787126586$

Maka $=(\mathrm{B} 15 / \mathrm{C} 15) * \mathrm{D} 15=\mathbf{0 , 5 3 5 2 4 6 0 7 9}$

Entropy individu $==+$ sheet 2 !N6 $=0,857148437$

Maka $=(\mathrm{B} 16 / \mathrm{C} 16) * \mathrm{D} 16=\mathbf{0 , 2 7 4 2 8 7 5}$

$=\operatorname{SUM}(\mathrm{E} 15: \mathrm{E} 16)=\mathbf{0 , 8 0 9 5 3 3 5 7 9}$

Jadi Gain pembeli node $1.1=0,970950594-0,809533579=\mathbf{0 , 1 6 1 4 1 7 0 1 6}$

Hasil perhitungan algoritma C4.5 dengan Microsoft excel 


\begin{tabular}{|c|c|c|c|c|c|c|c|}
\hline Total & & Total & 100 & 40 & 60 & 0.97095 & \\
\hline Node & Atribut & Nilai & Jumlah Kasus & Online & Offline & Entropy & Gain \\
\hline 1.1 & Pembeli & Reseller & 68 & 16 & 52 & 0.78712659 & \\
\hline & & Individu & 32 & 23 & 9 & 0.85714844 & 0.16142 \\
\hline & & & & & & & \\
\hline & Jenis Kopi & Arabica & 46 & 21 & 25 & 0.99453868 & \\
\hline & & Robusta & 19 & 6 & 13 & 0.89974376 & \\
\hline & & Blend & 35 & 13 & 22 & 0.95176268 & 0.00939 \\
\hline & & & & & & & \\
\hline & Harga & $>100 \mathrm{rb}$ & 62 & 10 & 52 & 0.6373875 & \\
\hline & & $<=100 \mathrm{rb}$ & 38 & 30 & 8 & 0.74248757 & 0.29363 \\
\hline
\end{tabular}

Gambar 6 Tabel hasil perhitungan entropy dan gain node 1.1

Dari hasil perhitungan diatas maka Gain node 1.1 yang tertinggi adalah harga dengan nilai 0,29363 .

\section{Decision Tree}

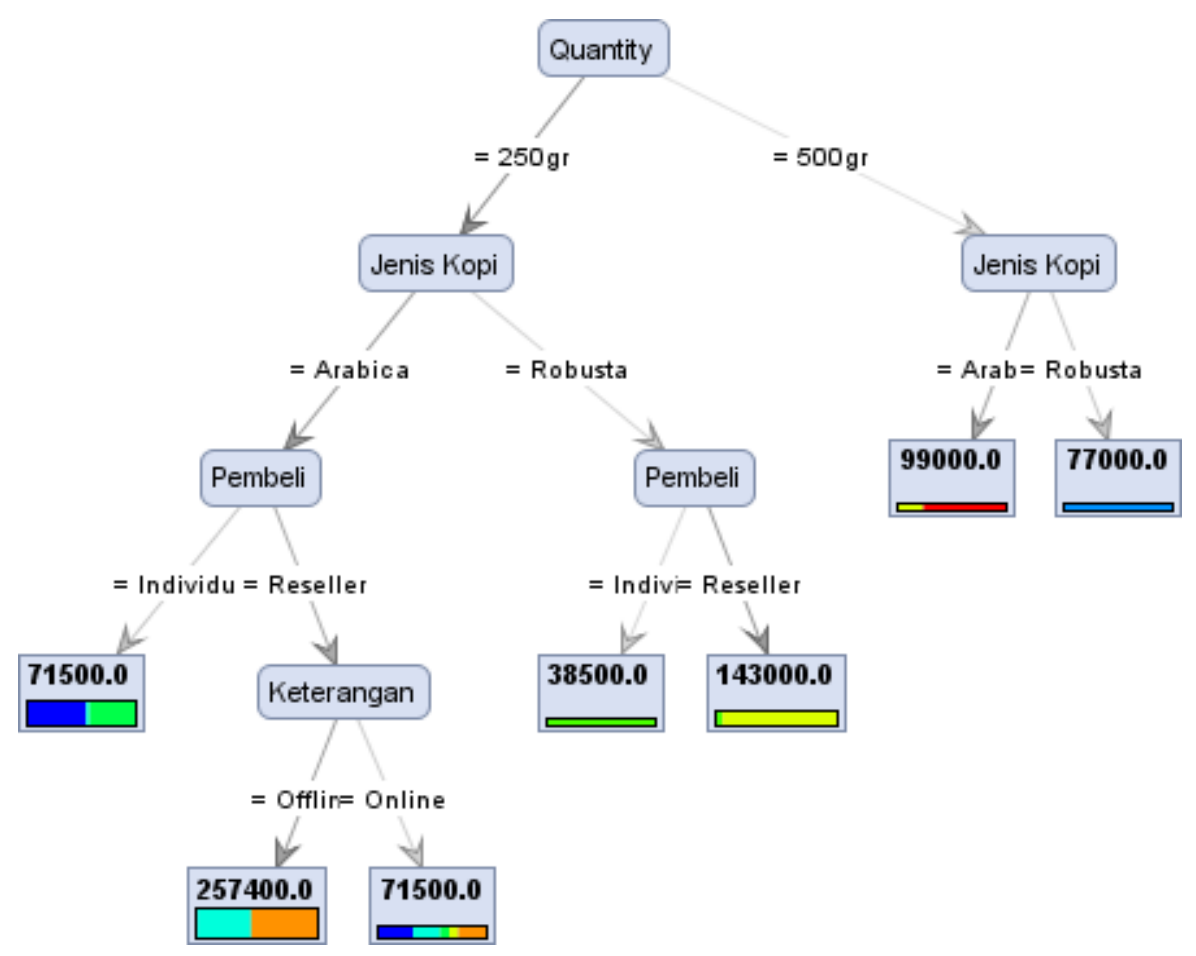

\section{Gambar 7. decision tree}

Bedasarkan perhitungan secara software rapidminer maka hasilnya ditentukan sebagai berikut: 
1. Quantity sebagai root.

2. Jika quantity 500gr maka jenis kopi Arabica harganya 99.000 dan jenis kopi robusta 77.000 .

3. Jika quantity $250 \mathrm{gr}$ maka jenis kopi robusta, pembeli individu dengan harga 38.500 dan pembeli reseller dengan harga 143.000.

4. Jika jenis kopi Arabica maka pembeli individu harganya 71.500.

5. Jika pembeli reseller maka yang membeli offline harganya 257.000 dan online harganya 71.500 .

\section{KESIMPULAN DAN SARAN}

Berdasarkan penelitian ini, maka peneliti mengakhiri perhitungan klasifikasi pengaruh penjualan kopi menggunakan metode Algortima C4.5 dengan kesimpulan sebagai berikut:

1. Berdasarkan perhitungan algoritma C4.5 yang dihitung secara manual menggunakan Microsoft excel bahwa pada tabel node 1 menggambarkan atribut quantity memiliki nilai gain tertinggi yaitu 0,62356. Dan pada tabel node 1.1 menggambarkan atribut harga memiliki nilai gain tertinggi yaitu 0,29363 juga mempengaruhi peningkatan penjualan kopi pada PT. JPW Indonesia.

2. Dengan perhitungan algoritma $\mathrm{C} 4.5$ menggunakan software rapidminer maka dapat diketahui decission tree adalah quantity sebagai root yang dapat mempengaruhi penjualan kopi.

3. Dengan demikian berdasarkan data yang telah dihitung menggunakan Microsoft excel dan rapidminer dengan metode Algoritma C4.5, maka dapat disimpulkan bahwa harga dan quantity menjadi indicator yang menyebabkan penjualan kopi pada PT. JPW Indonesia masih sering naik turun atau tidak stabil.

Setelah melaksanakan penelitian ini, maka peneliti memeberi saran bagi penelitian selanjutnya agar penelitian dapat dikembangkan di kemudian hari. Saran tersebut adalah:

1. Peneliti membuat penelitian ini dengan menggunakan metode klasifikasi Algoritma C4.5 untuk mengetahui pengaruh penjualan kopi. Kemudian peneliti berharap peneliti lain dapat mengembangkan dengan metode lain seperti Nä̈ve bayes, Nearest Neighbor, K-means maupun metode lainnya. 
2. Peneliti mendapatkan data mulai dari bulan Januari 2019 sampai Februari 2019 dengan mendapatkan 1087 data dari data penjualan kopi. Pada penelitian selanjutnya, peneliti berharap mendapat data dalam kurun waktu yang lebih lama dan mendapatkan jumlah data yang lebih banyak sehingga hasil yang didapatkan menjadi lebih tepat dan maksimal.

\section{REFERENSI}

Badrul, M. (2016). Algoritma asosiasi dengan algoritma apriori untuk analisa data penjualan. Pilar Nusa Mandiri, XII(2), 121-129. Retrieved from http://ejournal.nusamandiri.ac.id/ejurnal/index.php/pilar/article/view/169/14 5

Fauziah, U., Ihwana, A., Kalibrasi, J., Tinggi, S., Garut, T., \& Garut, K. (2014). Analisa rantai nilai distribusi kopi di kabupaten garut. (1).

Prof. Dr. Sugiyono. (2017a). Metode Penelitian Kuantitatif, Kualitatif, dan R\&D. ALFABETA, cv.

Prof. Dr. Sugiyono. (2017b). Metode Penelitian Kuantitatif, Kualitatif, dan R\&D. ALFABETA, cv.

Zahedi, B., Nahid-Mobarakeh, B., Pierfederici, S., \& Norum, L. E. (2016). A robust active stabilization technique for dc microgrids with tightly controlled loads. Proceedings - 2016 IEEE International Power Electronics and Motion Control Conference, PEMC 2016, VI(1), 254-260. https://doi.org/10.1109/EPEPEMC.2016.7752007 